\title{
Knockdown of long non-coding RNA HOTAIR inhibits proliferation and invasiveness and improves radiosensitivity in colorectal cancer
}

\author{
XIAO-DONG YANG ${ }^{1 *}$, HONG-TAO XU ${ }^{1 *}$, XIAO-HUI XU ${ }^{2}$, GAN RU $^{5}$, WEI LIU ${ }^{1}$, \\ JUN-JIA ZHU ${ }^{1}$, YONG-YOU WU ${ }^{1}$, KUI ZHAO ${ }^{1}$, YONG WU ${ }^{1}$, CHUN-GEN XING ${ }^{1}$, \\ SHU-YU ZHANG ${ }^{3,4}$, JIAN-PING CAO ${ }^{3,4}$ and MING $\mathrm{LI}^{3,4}$

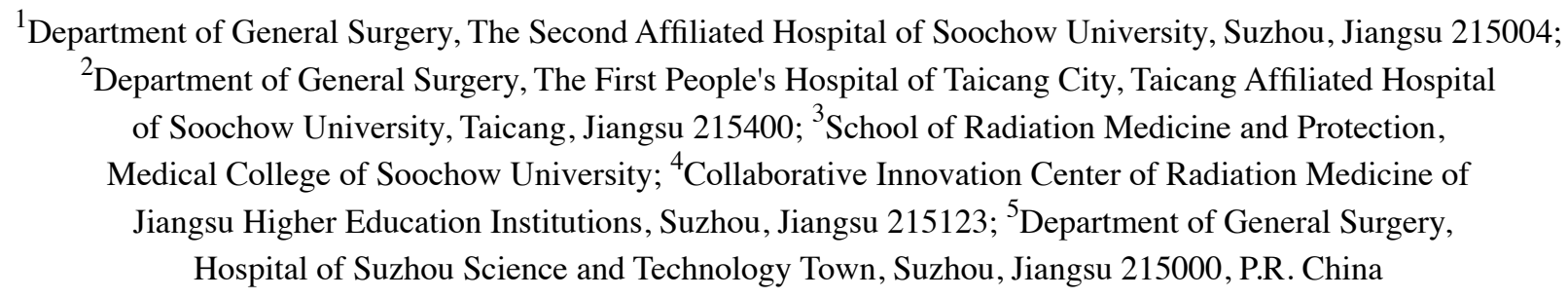

Received August 29, 2015; Accepted October 12, 2015

DOI: $10.3892 /$ or.2015.4397

\begin{abstract}
Colorectal cancer (CRC) is still one of the most important neoplasias causing human death. Multidisciplinary therapy has won consensus in the management of CRC, of which, radiotherapy occupies an important position. However, radioresistance is still a major obstacle in local control of CRC. Overexpression of long non-coding RNA HOTAIR has been found to correlate with tumorigenesis and poor prognosis in several types of cancer. In the present study, we analyzed HOTAIR expression levels of 53 CRC patients in tumor and adjacent normal tissue by real-time quantitative PCR. Knockdown of HOTAIR by RNA interference was performed to explore its roles in cell proliferation, migration, invasion, apoptosis and radiosensitivity. Results showed that CRC patients had higher HOTAIR expression in tumor tissues compared with adjacent normal tissues. In vitro, downregulation of HOTAIR reduced proliferation, migration and invasiveness while enhanced apoptosis and radiosensitivity of CRC cells. Taken together, our findings suggest that long non-coding RNA HOTAIR expression is closely associated
\end{abstract}

Correspondence to: Professor Chun-Gen Xing, Department of General Surgery, The Second Affiliated Hospital of Soochow University, Suzhou, Jiangsu 215004, P.R. China

E-mail: xingcg@126.com

Dr Ming Li, School of Radiation Medicine and Protection, Medical College of Soochow University, Suzhou, Jiangsu 215123, P.R. China E-mail:lim1984@suda.edu.cn

*Contributed equally

Key words: colorectal cancer, HOTAIR, radiosensitivity, proliferation, invasion, CCL244 with tumor invasion and radiosensitivity, indicating the potential role in diagnostics and therapeutics of CRC.

\section{Introduction}

Colorectal cancer (CRC) has high morbidity and mortality as one of the most common malignant tumors of human $(1,2)$. It is the second ranking newly diagnosed cancer and the second leading cause of overall cancer deaths (3). Radiotherapy occupies an important position in the treatment of CRC. Radiotherapy decreases the rate of local relapse and improves survival for stage II and III CRC (4). However, radioresistance is still an obstacle of radiotherapy in CRC. Therefore, it is necessary to improve our understanding of the occurrence and development of the disease and accurately predict tumor radioresistance.

Molecular techniques reveal that several genes are differently activated in CRC. Most attention has focused on the biological characteristics of protein-coding genes while ignoring non-coding RNA (ncRNA), the majority of human genome $(5,6)$. NcRNAs are divided into long ncRNAs (lncRNAs) and small ncRNAs based on size (7). LncRNAs are frequently $>200 \mathrm{nt}$ in length (8). Increasing research suggests that aberrant IncRNA expression may be a major contributor to tumorigenesis in numerous cancer types (9-12).

Recent finding suggested that HOTAIR functioned as a molecular scaffold to target PRC2 and LSD1 and ultimately caused epigenetic gene silencing promoting cancer metastasis (13). Aberrant HOTAIR expression significantly affects survival and prognosis of various types of cancers such as hepatocellular, breast, gastric, and pancreatic cancer (14). Upregulation of HOTAIR promotes metastasis and poor prognosis of esophageal squamous cell carcinoma (15). A recent study showed that suppressed expression of HOTAIR inhibited proliferation and tumorigenicity in renal carcinoma 
cells (16). However, the potential involvement of HOTAIR in radiosensitivity of CRC is so far unknown. In the present study, therefore, we explored the influence of HOTAIR knockdown on cell proliferation, migration, invasion, apoptosis and radiosensitivity.

\section{Materials and methods}

Clinical specimens. Fifty-three cases of fresh colorectal cancer (CRC) tissues and matched adjacent normal colorectal tissues were collected immediately after surgical resection and stored at $-80^{\circ} \mathrm{C}$ for further analysis. This study was conducted in accordance with the Declaration of Helsinki and with approval from the Ethics Committee of Soochow University. Table I shows the clinical characteristics of these patients.

Cell cultures and irradiation. All the cell lines (FHC, CCL244, HCT116, SW480 and LOVO) were purchased from Shanghai Institute of Cell Biology (Shanghai, China) and maintained in DMEM supplemented with $10 \%$ FBS and antibiotics (100 U/ml penicillin G, $100 \mathrm{U} / \mathrm{ml}$ streptomycin sulfates; Gibco, Grand Island, NY, USA) at $37^{\circ} \mathrm{C}$ in a humidified atmosphere containing $5 \% \mathrm{CO}_{2}$. Cells were exposed to a single dose of $\mathrm{X}$-ray irradiation from the linear accelerator (RadSource, Suwanee, GA, USA) at a dose rate of $1.15 \mathrm{~Gy} / \mathrm{min}$.

SiRNA construction and transfection. The siRNA sequences targeting human HOTAIR (si-HOTAIR) or negative control (NC) sequence were designed and synthesized by Genepharma (Shanghai, China) as shown in Table II. Cells were transfected with siRNA by Lipofectamine 2000 (Invitrogen, Carlsbad, CA, USA).

$R N A$ extraction, reverse transcription and real-time RT-PCR. Total RNA from tissues and cells was extracted using TRIzol reagent (Invitrogen). The reverse transcription of mRNAs was performed using a reverse transcription kit (Thermo-Fisher, Waltham, MA, USA). Amplification of cDNA template was performed by real-time RT-PCR using the SYBR Green kit (Tiangen, Beijing, China). Real-time RT-PCR was performed by the ABI7500 system (Applied Biosystems, Foster City, CA, USA). GAPDH was used as an endogenous standard, and HOTAIR values were normalized to GAPDH. The relative expression of HOTAIR was calculated by the 2- ${ }^{\Delta \Delta \mathrm{Ct}}$ method. The primer were designed and synthesized by Genepharma and the primer sequences are listed in Table III.

Cell proliferation assays. The effect of HOTAIR knockdown on cell viability was monitored by the MTT assay. Cells were seeded in 96 -well plates and cultured for 24,48 or $72 \mathrm{~h}$. Four hours before termination of culture, $20 \mu \mathrm{l}$ of $0.5 \mathrm{mg} / \mathrm{ml}$ MTT solution was added into each well, then the MTT solution was removed and $200 \mu \mathrm{l}$ DMSO was added. The supernatant solution was vibrated for $15 \mathrm{~min}$ and then placed in a microplate reader (Bio-Rad, Hercules, CA, USA) to measure the optical density (OD) value at the wavelength of $490 \mathrm{~nm}$. The viability index was calculated as the experimental OD value/the control OD value.

Colony-forming assay. Cell colony formation ability of CRC cells treated with siRNA transfection was measured by plate
Table I. Clinical characteristic of the CRC patients.

\begin{tabular}{lc} 
Clinical parameters & Numbers \\
\hline Cases & 53 \\
Age & \\
$\quad<65$ & 30 \\
$\geq 65$ & 23 \\
Tumor size & \\
Small size $(<5 \mathrm{~cm})$ & 25 \\
Large size $(\geq 5 \mathrm{~cm})$ & 28 \\
Gender & \\
Male & 35 \\
Female & 18
\end{tabular}

Invasion levels

Mucosa 4

Submucosa 3

Muscle $\quad 10$

Serosa 36

TNM stage

Stage 1-2

34

Stage 3-4

Lymph node metastasis

Positive 26

Negative 27

Grade of tumors

Low grade 13

Intermediate grade 33

$\begin{array}{ll}\text { High grade } & 7\end{array}$

Vascular invasion

Positive 22

Negative 31

Perineural invasion

Positive 17

Negative $\quad 36$

colony formation assay. Cells were seeded into 6-well plates at 300-8,000 cells/well depending on the dose of radiation. After irradiated with $0,2,4,6$ or 8 Gy X-ray irradiation, cells were incubated at $37^{\circ} \mathrm{C}$ for $10-14$ days to allow for colony formation. Then cells were fixed with $4 \%$ paraformaldehyde for $15 \mathrm{~min}$ and stained with Giemsa for $20 \mathrm{~min}$. Colony-forming efficiency (CFE) was calculated as follow: $\mathrm{CFE}=$ (number of colonies/number of seeded cells) x $100 \%$. Only viable colonies containing at least 50 cells were counted.

Cell cycle progression analysis. The detection of CCL244 cell cycle was assessed by flow cytometry $48 \mathrm{~h}$ after siRNA transfection. Cells were harvested by trypsin digestion, pelleted by centrifugation at $114 \mathrm{x} \mathrm{g}$ for $5 \mathrm{~min}$, washed with ice-cold PBS, then fixed with $75 \%$ cold ethanol overnight. The staining solution containing propidium iodide and DNase-free RNase 


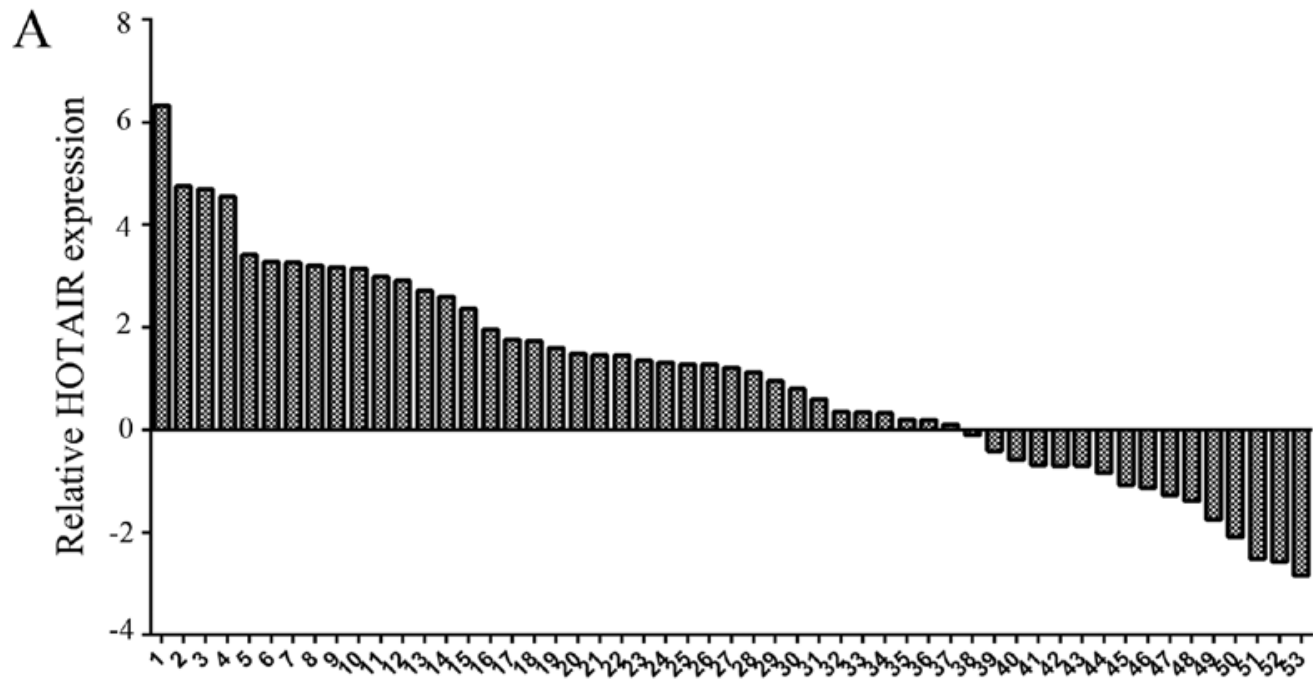

B

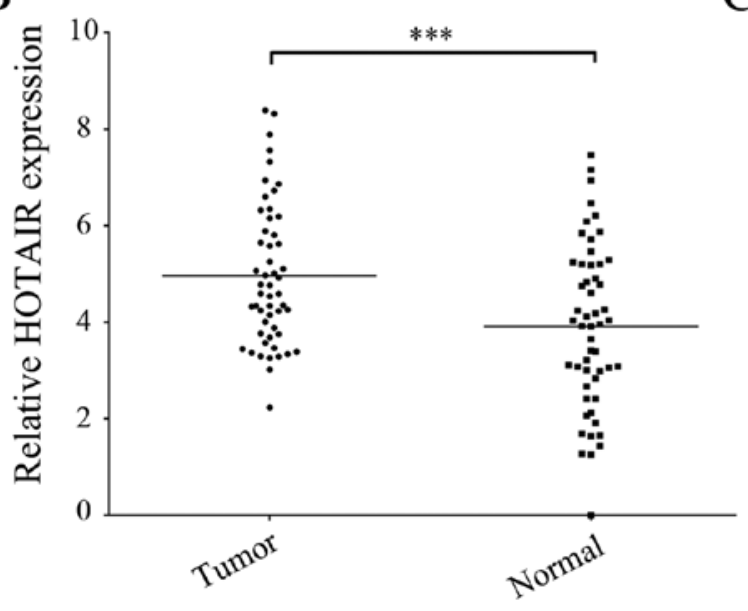

$\mathrm{C}$

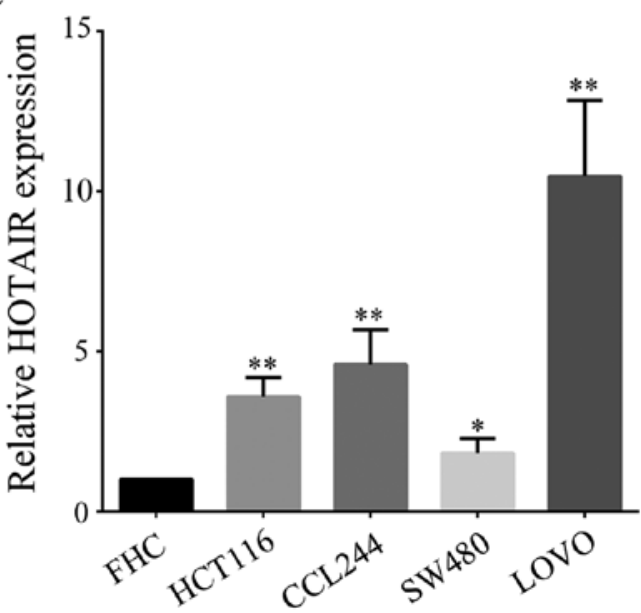

Figure 1. HOTAIR expression in CRC tissues and cells. (A) Real-time RT-PCR was used to detected the relative expression of HOTAIR in 53 pairs of human CRC cancerous and adjacent noncancerous tissues. GAPDH was used as an internal control. The - $\Delta \Delta \mathrm{Ct}$ (-[Tumor (CtHOTAIR-CtGAPDH) - Normal (CtHOTAIR-CtGAPDH)]) of HOTAIR in 53 pairs of human CRC cancerous and matched noncancerous tissues. (B) The mean - $\Delta C t$ [-(CtHOTAIR-CtGAPDH)] of HOTAIR in the $53 \mathrm{CRC}$ tissues was compared with that in the matched noncancerous tissues. (C) Relative expression of HOTAIR ( $2^{\wedge}$ - $\Delta \Delta \mathrm{Ct}$ ) in $4 \mathrm{CRC}$ cell lines (HCT116, CCL244, SW480, LOVO) and in one normal colonic mucosal cell line (FHC). ${ }^{*}<0.05,{ }^{* * *} \mathrm{P}<0.01,{ }^{* * * *} \mathrm{P}<0.001$, compared with normal tissues or normal colonic mucosal cell line.

was added 30 min before detection. Flow cytometric analysis was performed to determine the fraction of the population in each phase of the cell cycle using a Coulter flow cytometry (Beckman-Coulter, Brea, CA, USA).

Wound healing assay. CRC cells transfected with siRNA were seeded into 6-well plates. Then the confluent cell monolayers were scratched using a $200-\mu 1$ pipette tip, followed by removal of the supernatant and addition of fresh culture solution. The wound healing was detected using an inverted microscope (Olympus, Tokyo, Japan). The analysis of the cell migration assay was performed using the ImageJ software (National Institutes of Health, Bethesda, MD, USA).

Cell invasion assay. Cells $\left(5 \times 10^{4}\right)$ transfected with siRNA were seeded into the upper part of a Transwell ${ }^{\circledR}$ chamber (Corning Incorporated, Corning, NY, USA), which was pre-coated with $50 \mu \mathrm{l}$ matrigel for $1 \mathrm{~h}$, and $500 \mu 1$ DMEM medium containing $10 \%$ FBS was added into the lower part of the chamber. Cells were cultured at $37^{\circ} \mathrm{C}$ with $5 \% \mathrm{CO}_{2}$ for $24 \mathrm{~h}$ to allow the cells to migrate through the matrigel. The remaining cells on the upper surface were removed with a cotton swab moistened with PBS. Penetrated cells on the lower surface were fixed in ice-cold methanol for $30 \mathrm{~min}$ followed by staining with $2 \%$ crystal violet in methanol for 15 min and counted under an inverted microscope (Olympus, Tokyo, Japan). The cell number represented migration activity.

Cell apoptosis analysis. Cells were transfected with siRNA $24 \mathrm{~h}$ prior to treatment with sham or $6 \mathrm{~Gy}$ X-ray irradiation. The apoptosis rate of CRC cells was detected by flow cytometry. Cells $\left(5 \times 10^{5}\right)$ were washed with cold PBS at $179 \times \mathrm{g}$ for 5 min and then resuspended in $1 \mathrm{X}$ Annexin $\mathrm{V}$ binding buffer. The solution $(500 \mu \mathrm{l})$ was transferred to a culture tube and Annexin V-FITC and PI, $5 \mu \mathrm{l}$ each, was added. The solution was mixed and then incubated for $10 \mathrm{~min}$ at room temperature in the dark. Flow cytometric analysis was performed after $30 \mathrm{~min}$ of staining. 
A

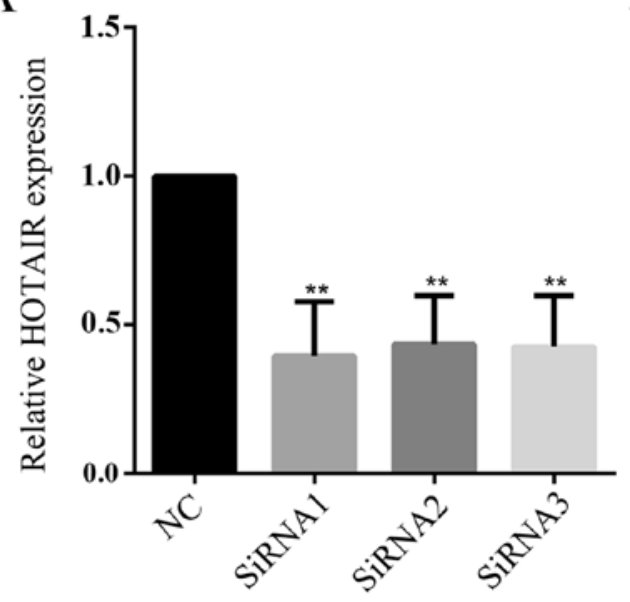

$\mathrm{B}$

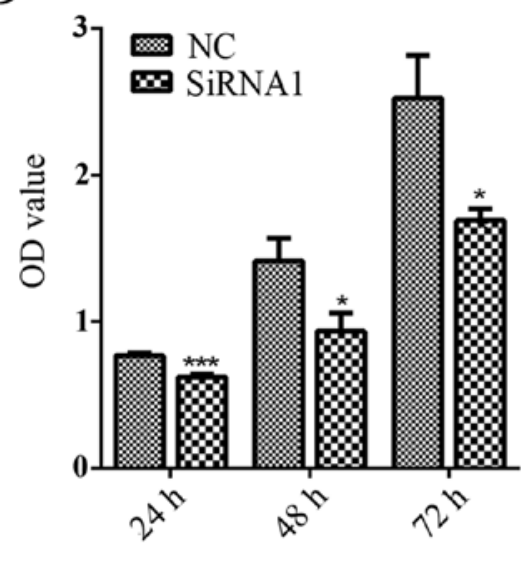

$\mathcal{C}$

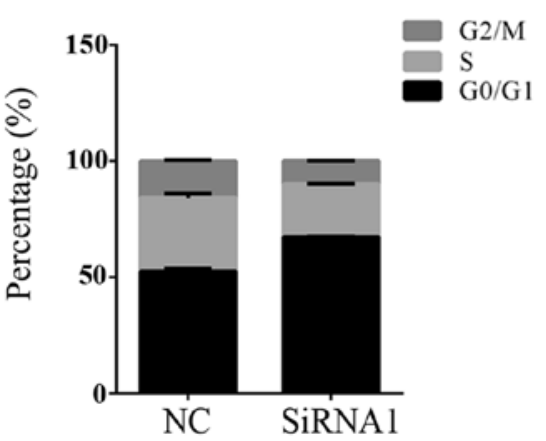

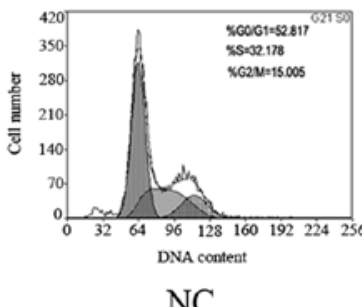

$\mathrm{NC}$

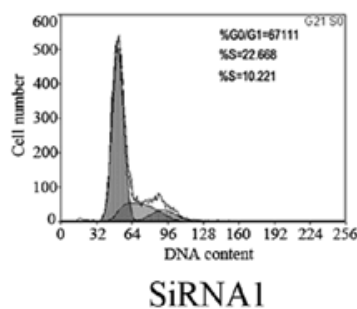

SiRNAl

Figure 2. Effect of HOTAIR silencing on cell proliferation. (A) The silencing efficiency of three siRNA sequences targeting HOTAIR gene was confirmed by real-time RT-PCR. (B) The effect of HOTAIR silencing on cell viability of CCL244 cells was detected by MTT assay. (C) Calculated cell cycle distribution and representative charts in HOTAIR knock-down and the control cells. ${ }^{*} \mathrm{P}<0.05,{ }^{* * *} \mathrm{P}<0.01,{ }^{* * * *} \mathrm{P}<0.001$, compared with negative control (NC) siRNA group.

Table II. Target sequences of HOTAIR siRNAs or negative control (NC) siRNA.

\begin{tabular}{lc}
\hline siRNA & \multicolumn{1}{c}{ Target sequences } \\
\hline si-HOTAIR1 & \\
Sense & 5'-GCGCCUUCCUUAUAAGUAUTT-3' \\
Antisense & 5'-AUACUUAUAAGGAAGGCGCTT-3' \\
si-HOTAIR2 & \\
Sense & 5'-GCACAGAGCAACUCUAUAATT-3' \\
Antisense & 5'-UUAUAGAGUUGCUCUGUGCTT-3' \\
si-HOTAIR3 & \\
Sense & 5'-GAGGCGCUAAUUAAUUGAUTT-3' \\
Antisense & 5'-AUCAAUUAAUUAGCGCCUCTT-3' \\
NC & \\
Sense & 5'-UUCUCCGAACGUGUCACGUTT-3' \\
Antisense & 5'-ACGUGACACGUUCGGAGAATT-3'
\end{tabular}

Western blotting. Cells were transfected with siRNA $24 \mathrm{~h}$ prior to treatment with sham or 6 Gy X-ray irradiation. The cells were washed with PBS and then harvested in lysis buffer with $1 \mathrm{mM}$ PMSF on ice. The proteins extracted from supernatants were separated on $10 \%$ polyacrylamide gels and subsequently transferred onto PVDF membranes. For immunoblotting analysis, PVDF membranes were incubated with specific antibodies recognizing target proteins at $4^{\circ} \mathrm{C}$ overnight. After washing with TBST for three times, the membranes were then incubated with corresponding HRP conjugated secondary antibody (1:1000) for $1 \mathrm{~h}$ at room temperature. Finally the membranes were analyzed by ECL detection system and visualized by FluroChem MI imaging system (Alpha Innotech Corp., Santa Clara, CA, USA). The primary antibodies were MMP2, MMP9 (1:1000; Cell Signaling Technology, Boston, MA, USA), Bax and Bcl-2 (1:1000; Santa Cruz Biotechnology, Santa Cruz, CA, USA). Protein GAPDH (1:1000; Sigma-Aldrich, St. Louis, MO, USA) was used as loading controls.

Statistical analysis. Statistical analysis was performed using SPSS 19.0. Data are presented as mean \pm SEM. The Student's $\mathrm{t}$-test was used to measure the difference between two groups. The differences among three or more groups were tested for significance using one-way analysis of variance. $\mathrm{P}<0.05$ was considered to be statistically significant.

\section{Results}

Overexpression of HOTAIR in human CRC. The expression level of HOTAIR in 53 pairs of human CRC and matched adjacent normal tissues was detected by real-time RT-PCR. Fig. 1A and B showed the overexpression of HOTAIR in $53 \mathrm{CRC}$ tissues compared to their non-tumorous counterparts. 
Table III. Primer sequences for qRT-PCR analysis.

\begin{tabular}{lcc}
\hline Gene & Forward sequence & Reverse sequence \\
\hline HOTAIR & 5'-AAACAGAGTCCGTTCAGTGTCA-3' & 5'-ATTCTTAAATTGGGCCTGGGTC-3' \\
GAPDH & 5'-CATGAGAAGTATGACAACAGCCT-3' & 5'-AGTCCTTCCACGATACCAAAGT-3'
\end{tabular}

Furthermore, the expression level of HOTAIR in 5 cell lines including one normal colonic mucosal cell line (FHC) and 4 CRC cell lines (HCT116, CCL244, SW480, LOVO) was also determined by real-time RT-PCR. Our results showed that the expression of HOTAIR in HCT116, CCL244, SW480 and LOVO CRC cells was higher than that in FHC cells (Fig. 1C). These results indicated that HOTAIR was highly expressed in CRC tumor tissues and cell lines. Our previous study has demonstrated that the ascending order of these four CRC cell lines in terms of radiosensitivity was CCL244, SW480, LOVO and HCT116 (17). Therefore, CCL244 cell line was selected to perform the following experiments.

HOTAIR silencing inhibits the proliferation of CRC cells. CCL244 cells were transfected with siRNA against HOTAIR to further explore the role of HOTAIR in proliferation. Three different siRNA vectors were designed to knockdown the coding gene of HOTAIR and the silencing efficiency of these siRNA vectors was detected by real-time RT-PCR. The results revealed that the silencing efficiency of siRNA1, siRNA2 and siRNA3 was respectively 39.6, 43.5 and $42.6 \%$ (Fig. 2A). Therefore, siRNA1 was selected to perform the following experiments. MTT assay showed that knockdown of HOTAIR caused $18.8 \%(\mathrm{P}=0.0008), 33.9 \%(\mathrm{P}=0.0403)$ and $33.1 \%(\mathrm{P}=0.0242)$ reduction in the cell viability at 24,48 and $72 \mathrm{~h}$ after siRNA transfection compared with negative control (NC) siRNA-transfected cells (Fig. 2B). Furthermore, cell cycle progression analysis demonstrated that the population of cells in G0/G1 phase was increased and the percentage of cells in $\mathrm{S}$ phase was significantly decreased in HOTAIR knockdown cells (Fig. 2C). Taken together, these results revealed that HOTAIR knock-down obviously inhibited CCL244 cell proliferation through blocking cells in G0/G1 phase.

Knockdown of HOTAIR increases the radiosensitivity of CCL244 cells. Clonogenic survival assay was performed to explore the influence of HOTAIR on radiosensitivity of CCL244 CRC cells. The dose-survival curves of CCL244 cells were obtained according to the multi-target single hit model. Results showed that HOTAIR-silencing caused a significant dose-dependent radiosensitization in CCL244 cells (Fig. 3). The mean lethal dose (D0) for cells treated with radiation alone was $1.85 \mathrm{~Gy}$, while cells treated with irradiation plus HOTAIR silencing exhibited a D0 of $1.18 \mathrm{~Gy}$. The quasi-threshold dose $(\mathrm{Dq})$ in radiation alone and radiation plus HOTAIR silencing group was 1.44 Gy and $1.12 \mathrm{~Gy}$, respectively. The sensitizer enhancement ratio (SER) was 1.57 for cells treated with radiation plus HOTAIR silencing, compared to cells treated with radiation alone. Therefore, these results demonstrated that downregulation of HOTAIR significantly increased the radiosensitivity of CCL244 cells.

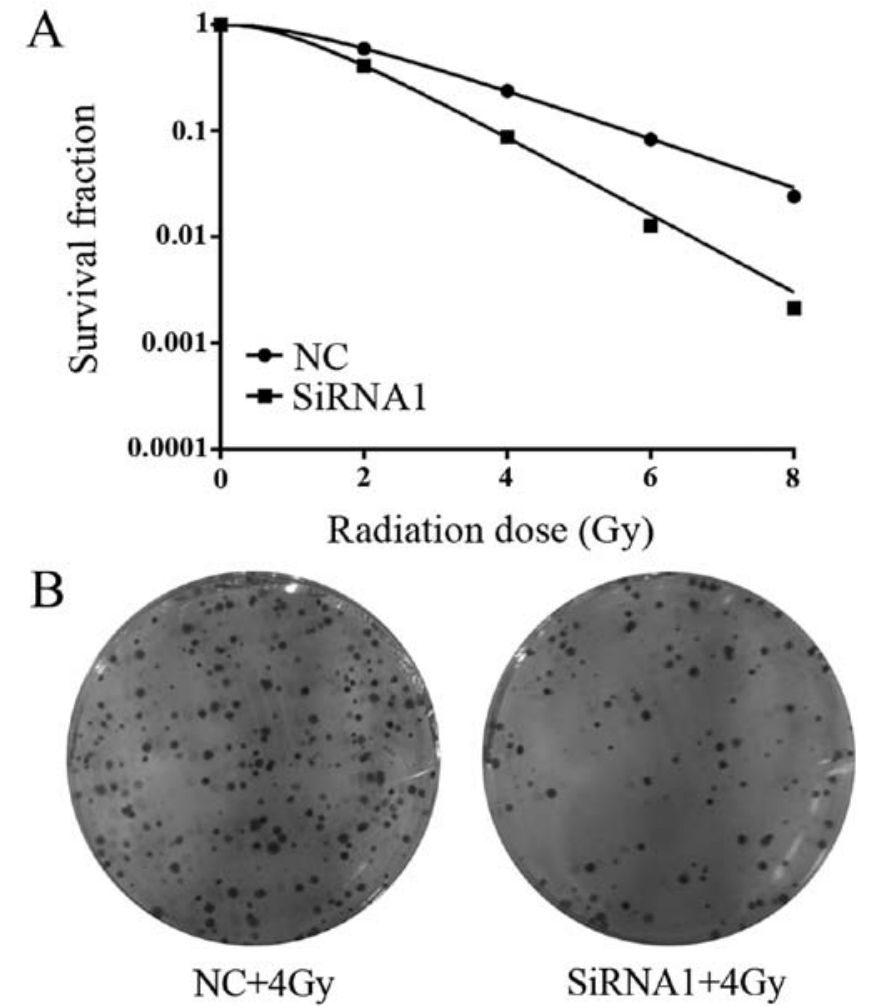

Figure 3. Clonogenic survival rate of CCL244 cells after knock-down of HOTAIR combined with X-ray irradiation. (A) Clonogenic cell survival curve of HOTAIR knockdown and negative control (NC) CCL244 cells exposed to 2, 4, 6 or 8 Gy of X-ray irradiation. (B) Representative colony images of HOTAIR knockdown and NC CCL244 cells exposed to 4 Gy X-ray irradiation.

HOTAIR silencing increases radiation-induced apoptosis in CCL244 cells and regulated the expression of apoptosisrelated proteins. To further investigate the role of HOTAIR in radiation-induced apoptosis, flow cytometry was used to detect the percentage of apoptotic cells in HOTAIR silenced CCL244 cells with or without irradiation. As shown in Fig. 4A and 4B, 6 Gy $\mathrm{X}$ ray irradiation induced apoptosis in CCL244 cells (NC 6.63\% vs. NC+IR 21.99\%, $\mathrm{P}=0.0033$ ). HOTAIR silencing further enhanced the apoptosis response to $6 \mathrm{~Gy} \mathrm{X}$ ray $(\mathrm{NC}+\mathrm{IR}$ $21.99 \%$ vs. siRNA1+IR 44.41\%, $\mathrm{P}=0.0039$ ). Furthermore, HOTAIR silencing CCL244 cells combined with irradiation showed downregulation of anti-apoptotic protein Bcl-2 and upregulation of pro-apoptotic protein Bax (Fig. 4C). These results demonstrated that HOTAIR knockdown significantly increased radiation-induced apoptosis in CCL244 cells.

Knockdown of HOTAIR inhibits the invasion and migration of CCL244 cells after irradiation. Metastasis and invasion are the most important prognostic factors in patients with CRC. 

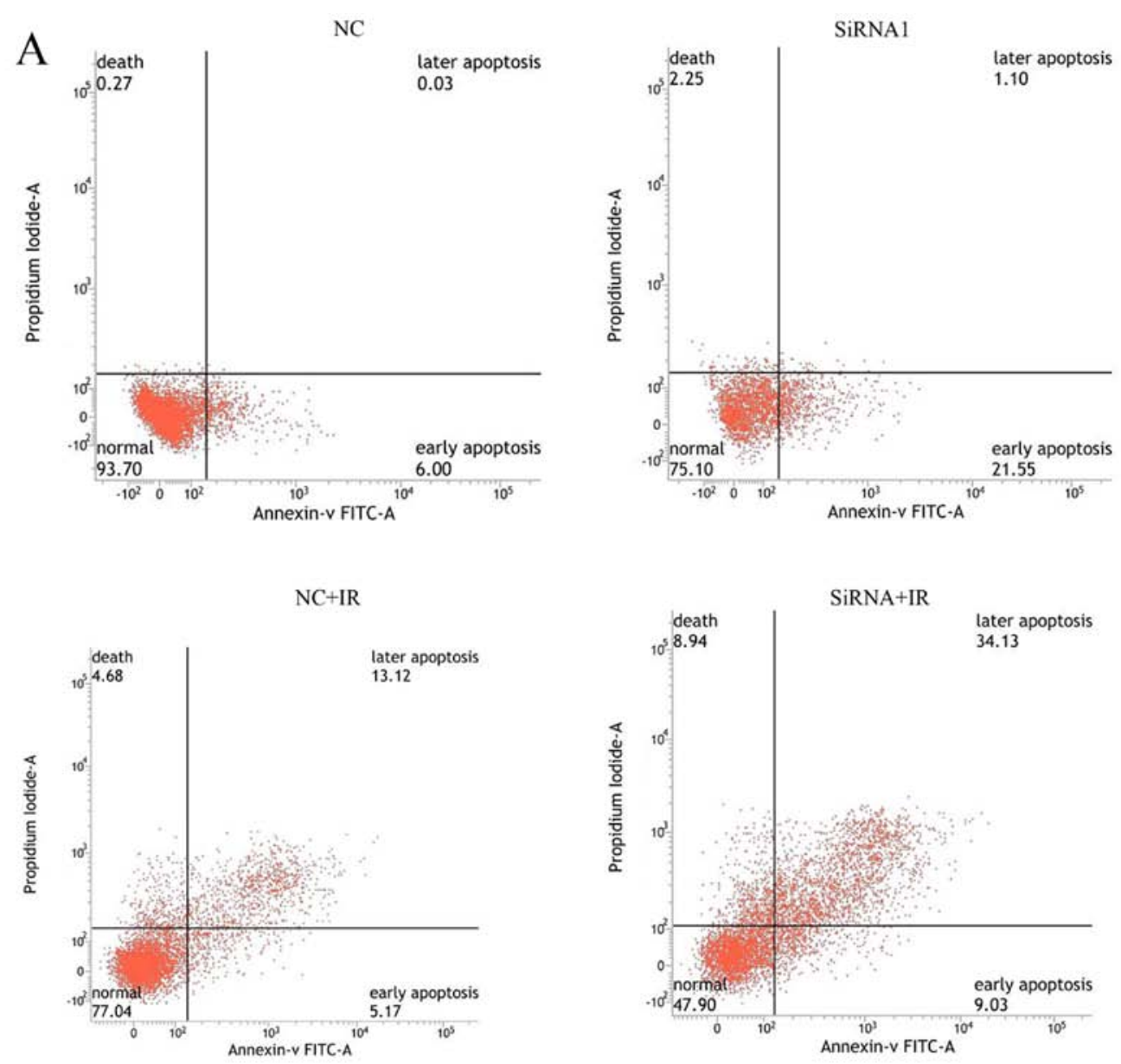

$\mathrm{B}$

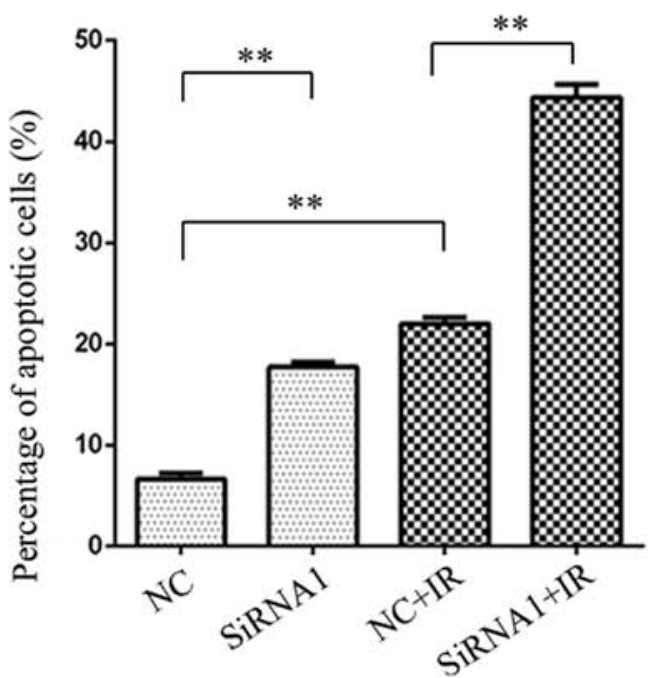

$\mathrm{C}$

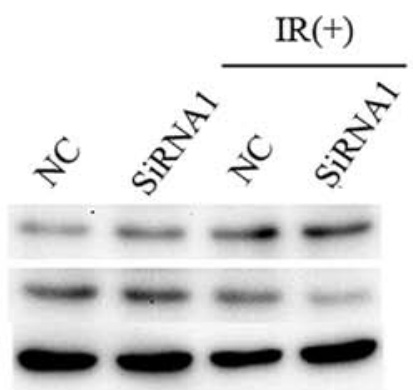

Figure 4. HOTAIR silencing enhanced the radiation-induced apoptosis. (A) Apoptosis were measured using Annexin V/PI staining in HOTAIR silencing CCL244 cells combined with irradiation (IR). (B) Percentage of apoptotic cells in HOTAIR siRNA transfected and negative control (NC) siRNA transfected cells subjected to 0 and 6-Gy X-ray irradiation. (C) Western blot analysis of apoptosis related proteins Bax and Bcl-2 in CCL244 cells. GAPDH was used as an internal control. ${ }^{* *} \mathrm{P}<0.01$, compared with negative control (NC) siRNA group or NC siRNA plus irradiation group.

Transwell matrigel invasion and wound healing assays were performed to further explore the participation of HOTAIR in cell metastasis. As shown in Fig. 5A, knockdown of HOTAIR inhibited the invasiveness of CCL244 cells compared with negative control (NC) CCL244 cells $(\mathrm{P}=0.0005)$. HOTAIR silencing CCL244 cells combined with 6 Gy X-ray irradiation showed obvious inhibition in invasiveness compared with cells treated with 6 Gy X-ray radiation alone $(\mathrm{P}=0.0008)$. As shown in Fig. 5B, knockdown of HOTAIR inhibited the migration of CCL244 cells compared with (NC) CCL244 cells $(\mathrm{P}=0.0029)$. HOTAIR silencing CCL244 cells combined with 6 Gy X-ray irradiation showed obvious inhibition in 
A

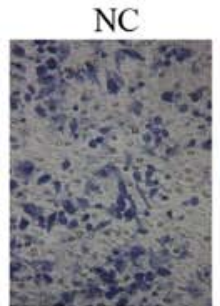
SiRNA1
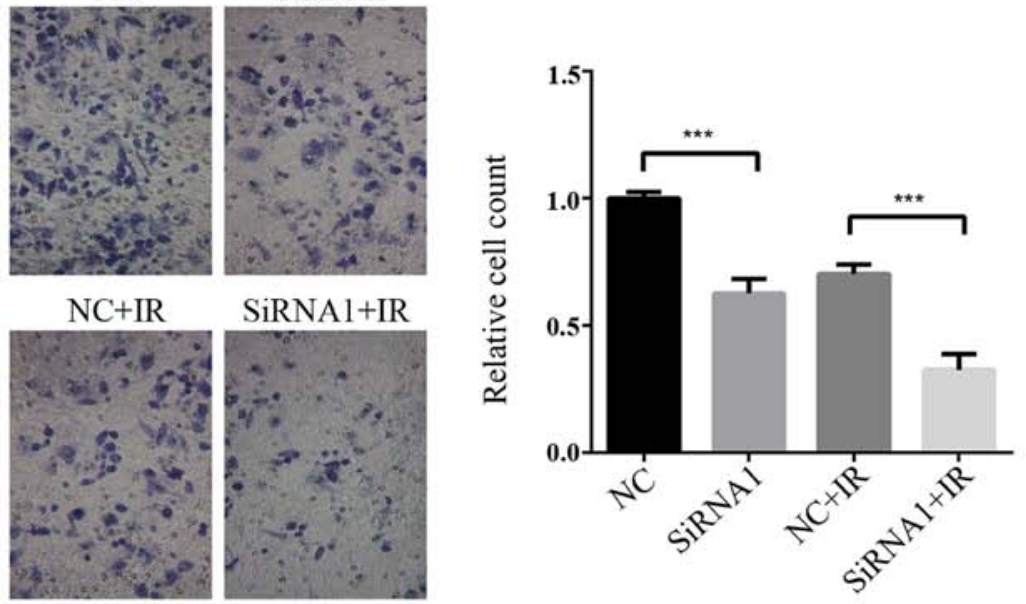

B

SiRNA1+IR
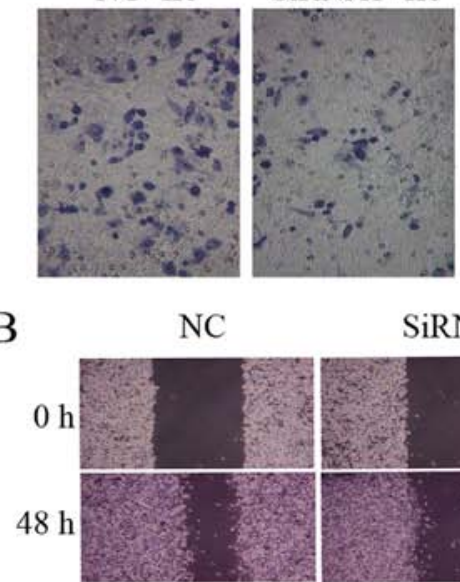

SiRNA1
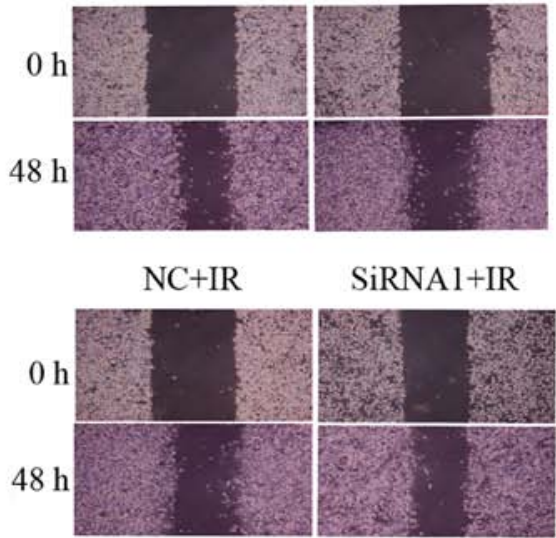

SiRNAl+IR
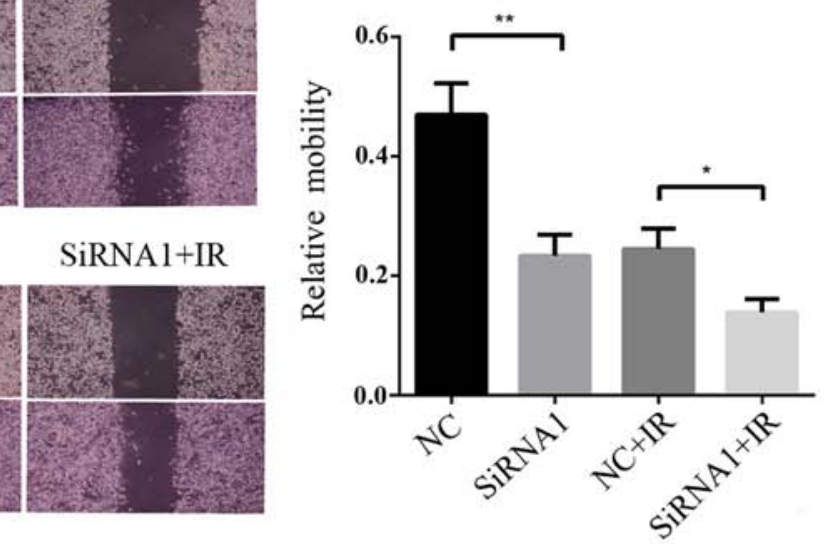

C

\section{$\operatorname{IR}(+)$}

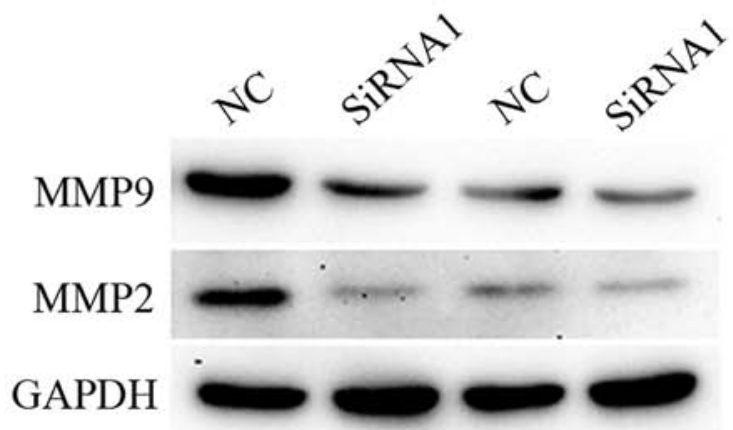

Figure 5. Effect of HOTAIR silencing on cell invasion and migration. (A) Transwell matrigel invasion assays of CCL244 cells after transfected with siRNA1 prior to 6 Gy X-ray irradiation (IR). (B) Wound healing assays of CCL244 cells after HOTAIR silencing combined with 6 Gy X-ray irradiation. (C) The expression level of MMP2 and MMP9 in HOTAIR silencing CCL244 cells combined with 6 Gy X-ray irradiation was detected by western blotting. GAPDH was used as an internal control. ${ }^{*} \mathrm{P}<0.05,{ }^{* *} \mathrm{P}<0.01,{ }^{* * * *} \mathrm{P}<0.001$, compared with negative control (NC) siRNA group or negative control (NC) siRNA plus irradiation group.

migration compared with cells treated with 6 Gy X-ray radiation alone $(\mathrm{P}=0.0108)$. As a family of extracellular matrix degrading enzymes, matrix metalloproteinases (MMPs) are expressed in various stages of CRC and participate in tumor invasion and metastasis (18). The expression level of some MMPs was also detected by western blotting. As shown in Fig. 5C, HOTAIR silencing CCL244 cells combined with irradiation showed downregulation of MMP2 and MMP9. Therefore, these results indicated that HOTAIR silencing significantly inhibited the invasion and migration of CCL244 cells after irradiation.

\section{Discussion}

Long non-coding RNAs (lncRNAs) are emerging as key regulators of diverse cellular processes $(19,20)$. As the first found IncRNA, HOTAIR is co-expressed with the HOXC gene cluster to regulate various genes through reverse 
transcription $(21,22)$. Numerous evidence has shown that dysregulation of HOTAIR was closely associated with tumor metastasis and poor prognosis (23-26). However, the function role of HOTAIR in CRC proliferation, invasion, radiationinduced apoptosis and radiosensitivity is still being explored.

It is reported that HOTAIR is highly expressed in various types of cancers such as primary breast tumors, hepatocellular carcinoma, and gastrointestinal stromal tumors (27-29). The present study examined the expression level of HOTAIR in $\mathrm{CRC}$ tissues and matched normal tissues. Results showed that the HOTAIR level was significantly upregulated in CRC cancer tissues compared with adjacent normal tissues. Furthermore, CRC cell lines showed high expression level of HOTAIR compared with normal colonic mucosal cell line. The above evidence reveals the important role of HOTAIR in CRC tumorigenesis.

To further explore the role of HOTAIR in CRC, we investigated the effects of HOTAIR knockdown on CRC cell proliferation. MTT assay revealed that RNAi-mediated suppression of HOTAIR led to a significant inhibition in CCL244 cell viability. Furthermore, HOTAIR silencing results in a significant inhibition in the proliferation through blocking cells in G0/G1 phase. Therefore, HOTAIR knockdown can inhibit the proliferation in CRC and HOTAIR represents a new promising target and a prognosis marker for CRC therapy.

It was demonstrated that HOTAIR is a negative prognostic factor and HOTAIR silencing results in inhibition of cell invasion in pancreatic tumors (30). Xu et al found that HOTAIR promoted epithelial-mesenchymal transition (EMT) through regulating snail expression thus contributing to gastric cancer metastasis (31). Furthermore, HOTAIR may promote tumor aggressiveness through the upregulation of VEGF and MMP-9 and EMT-related genes (32). Additionally, it is reported that HOTAIR promotes tumor cell invasion and metastasis by recruiting EZH2 and repressing E-cadherin in squamous cell carcinoma (33). We performed Transwell invasion and wound healing assays to further explore the influence of HOTAIR knockdown and irradiation treatment on cell migration and invasion. Results showed that irradiation treatment caused an obvious inhibition in cell invasion and HOTAIR silencing further enhanced the inhibition response to irradiation. Furthermore, western blotting was performed to detect the metastasis-related proteins of MMPs to support the role of HOTAIR in CRC metastasis mechanically. Similarly, the present study demonstrated that HOTAIR silencing plus irradiation treatment significantly suppressed the expression of MMP2 and MMP9, indicating the promoting effect of HOTAIR in cancer metastasis. This phenomenon indicates that HOTAIR may function as an oncogene in CRC tumorigenesis.

Apoptotic cell death is involved in almost every mode of cell death. Radiation induced cell death is closely associated with apoptosis. Dysregulation of apoptotic genes such as caspase-3, Bax, and Bcl-2 may play a key role in radiation induced cell death (34). HOTAIR has been found to promote the proliferation of serous ovarian cancer cells through the regulation of cell cycle arrest and apoptosis (35). Recently, it was reported that calycosin and genistein induce apoptosis by inactivation of HOTAIR/p-Akt signaling pathway in human breast cancer MCF-7 cells (36). Consistent with these studies, we also observed a significant increase in the apoptotic cell population following HOTAIR silencing plus irradiation treatment. Furthermore, HOTAIR silenced CRC cells plus irradiation treatment showed a significant increase in pro-apoptotic protein Bax levels and decrease in anti-apoptotic protein Bcl-2 levels. In conclusion, irradiation treatment induced apoptosis in CRC CCL244 cells and HOTAIR silencing further enhanced the apoptotic response to $\mathrm{X}$ ray irradiation.

Few studies have addressed the role of HOTAIR in cancer cell radiosensitivity. Wang et al found that Curcumin enhances the radiosensitivity in nasopharyngeal carcinoma cells involving the reversal of differentially expressed long non-coding RNAs (37). Several experiments were performed to further evaluate the role of HOTAIR in CCL244 CRC cell radiosensitivity in our study. Flow cytometry showed that knockdown of HOTAIR significantly increased the radiationinduced apoptosis in CCL244 cells. Furthermore, the SER of HOTAIR knockdown was 1.57 in the clone formation assay. Therefore, our finding indicates that HOTAIR knockdown sensitized CCL244 cells to irradiation. However, the underlying mechanism needs further exploration.

In summary, the present study showed that HOTAIR was overexpressed in CRC and HOTAIR silencing inhibited the proliferation and metastasis and enhanced the radiosensitivity in CCL244 cells. These results indicate that targeting HOTAIR may serve as a potentially novel approach for CRC diagnosis and therapy.

\section{Acknowledgements}

This study was partially supported by the National Natural ScienceFoundation of China (grant no.81172348 and 81301933), Health Research Projects in Jiangsu Province (H201313), the projects of Suzhou City Technology Bureau (SYSD2013090) and the Priority Academic Program Development of Jiangsu Higher Education Institutions (PAPD).

\section{References}

1. DeSantis CE, Lin CC, Mariotto AB, Siegel RL, Stein KD, Kramer JL, Alteri R, Robbins AS and Jemal A: Cancer treatment and survivorship statistics, 2014. CA Cancer J Clin 64: 252-271, 2014.

2. Karsa LV, Lignini TA, Patnick J, Lambert R and Sauvaget C: The dimensions of the CRC problem. Best Pract Res Clin Gastroenterol 24: 381-396, 2010.

3. Karim-Kos HE, de Vries E, Soerjomataram I, Lemmens V, Siesling S and Coebergh JW: Recent trends of cancer in Europe: A combined approach of incidence, survival and mortality for 17 cancer sites since the 1990s. Eur J Cancer 44: 1345-1389, 2008.

4. Lacombe J, Azria D, Mange A and Solassol J: Proteomic approaches to identify biomarkers predictive of radiotherapy outcomes. Expert Rev Proteomics 10: 33-42, 2013.

5. Nie L, Wu HJ, Hsu JM, Chang SS, Labaff AM, Li CW, Wang Y, Hsu JL and Hung MC: Long non-coding RNAs: versatile master regulators of gene expression and crucial players in cancer. Am J Transl Res 4: 127-150, 2012.

6. Hajjari M, Khoshnevisan A and Shin YK: Molecular function and regulation of long non-coding RNAs: Paradigms with potential roles in cancer. Tumour Biol 35: 10645-10663, 2014.

7. Li G, Zhang H, Wan X, Yang X, Zhu C, Wang A, He L, Miao R, Chen $S$ and Zhao H: Long noncoding RNA plays a key role in metastasis and prognosis of hepatocellular carcinoma. Biomed Res Int 2014: 780521, 2014.

8. Sarkar SP and Adshead G: Whose DNA is it anyway? European court, junk DNA, and the problem with prediction. J Am Acad Psychiatry Law 38: 247-250, 2010. 
9. Popov $\mathrm{N}$ and Gil J: Epigenetic regulation of the INK4bARF-INK4a locus: In sickness and in health. Epigenetics 5: 685-690, 2010.

10. Kotake Y, Nakagawa T, Kitagawa K, Suzuki S, Liu N, Kitagawa M and Xiong Y: Long non-coding RNA ANRIL is required for the PRC2 recruitment to and silencing of p15(INK4B) tumor suppressor gene. Oncogene 30: 1956-1962, 2011

11. Wojcik SE, Rossi S, Shimizu M, Nicoloso MS, Cimmino A, Alder H, Herlea V, Rassenti LZ, Rai KR, Kipps TJ, et al: Non-codingRNA sequence variations in human chronic lymphocytic leukemia and colorectal cancer. Carcinogenesis 31: 208-215, 2010

12. Calin GA, Liu CG, Ferracin M, Hyslop T, Spizzo R, Sevignani C Fabbri M, Cimmino A, Lee EJ, Wojcik SE, et al: Ultraconserved regions encoding ncRNAs are altered in human leukemias and carcinomas. Cancer Cell 12: 215-229, 2007.

13. Wu Y, Zhang L, Wang Y, Li H, Ren X, Wei F, Yu W, Wang X, Zhang L, Yu J, et al: Long noncoding RNA HOTAIR involvement in cancer. Tumour Biol 35: 9531-9538, 2014.

14. Cai B, Song XQ, Cai JP and Zhang S: HOTAIR: A cancer-related long non-coding RNA. Neoplasma 61: 379-391, 2014.

15. Chen FJ, Sun M, Li SQ, Wu QQ, Ji L, Liu ZL, Zhou GZ, Cao G Jin L, Xie HW, et al: Upregulation of the long non-coding RNA HOTAIR promotes esophageal squamous cell carcinoma metastasis and poor prognosis. Mol Carcinog 52: 908-915, 2013.

16. Wu Y, Liu J, Zheng Y, You L, Kuang D and Liu T: Suppressed expression of long non-coding RNA HOTAIR inhibits proliferation and tumourigenicity of renal carcinoma cells. Tumour Biol 35: 11887-11894, 2014.

17. Yang XD, Xu XH, Zhang SY, Wu Y, Xing CG, Ru G, Xu HT and Cao JP: Role of miR-100 in the radioresistance of colorecta cancer cells. Am J Cancer Res 5: 545-559, 2015.

18. Wagenaar-Miller RA, Gorden L and Matrisian LM: Matrix metalloproteinases in colorectal cancer: Is it worth talking about? Cancer Metastasis Rev 23: 119-135, 2004.

19. Cabili MN, Trapnell C, Goff L, Koziol M, Tazon-Vega B, Regev A and Rinn JL: Integrative annotation of human large intergenic noncoding RNAs reveals global properties and specific subclasses. Genes Dev 25: 1915-1927, 2011.

20. Kogo R, Shimamura T, Mimori K, Kawahara K, Imoto S, Sudo T, Tanaka F, Shibata K, Suzuki A, Komune S, et al: Long noncoding RNA HOTAIR regulates polycomb-dependent chromatin modification and is associated with poor prognosis in colorectal cancers. Cancer Res 71: 6320-6326, 2011.

21. Rinn JL, Kertesz M, Wang JK, Squazzo SL, Xu X, Brugmann SA Goodnough LH, Helms JA, Farnham PJ, Segal E, et al: Functional demarcation of active and silent chromatin domains in human HOX loci by noncoding RNAs. Cell 129: 1311-1323, 2007.

22. Tsai MC, Manor O, Wan Y, Mosammaparast N, Wang JK, Lan F, Shi Y, Segal E and Chang HY: Long noncoding RNA as modular scaffold of histone modification complexes. Science 329: 689-693, 2010

23. Lu L, Zhu G, Zhang C, Deng Q, Katsaros D, Mayne ST, Risch HA, Mu L, Canuto EM, Gregori G, et al: Association of large noncoding RNA HOTAIR expression and its downstream intergenic $\mathrm{CpG}$ island methylation with survival in breast cancer. Breast Cancer Res Treat 136: 875-883, 2012.

24. Gupta RA, Shah N, Wang KC, Kim J, Horlings HM, Wong DJ, Tsai MC, Hung T, Argani P, Rinn JL, et al: Long non-coding RNA HOTAIR reprograms chromatin state to promote cancer metastasis. Nature 464: 1071-1076, 2010.
25. Yang Z, Zhou L, Wu LM, Lai MC, Xie HY, Zhang F and Zheng SS: Overexpression of long non-coding RNA HOTAIR predicts tumor recurrence in hepatocellular carcinoma patients following liver transplantation. Ann Surg Oncol 18: 1243-1250, 2011.

26. Nie Y, Liu X, Qu S, Song E, Zou H and Gong C: Long noncoding RNA HOTAIR is an independent prognostic marker for nasopharyngeal carcinoma progression and survival. Cancer Sci 104: 458-464, 2013.

27. Geng YJ, Xie SL, Li Q, Ma J and Wang GY: Large intervening non-coding RNA HOTAIR is associated with hepatocellular carcinoma progression. J Int Med Res 39: 2119-2128, 2011.

28. Niinuma T, Suzuki H, Nojima M, Nosho K, Yamamoto H, Takamaru H, Yamamoto E, Maruyama R, Nobuoka T, Miyazaki Y, et al: Upregulation of miR-196a and HOTAIR drive malignant character in gastrointestinal stromal tumors. Cancer Res 72: 1126-1136, 2012.

29. Ishibashi M, Kogo R, Shibata K, Sawada G, Takahashi Y, Kurashige J, Akiyoshi S, Sasaki S, Iwaya T, Sudo T, et al: Clinical significance of the expression of long non-coding RNA HOTAIR in primary hepatocellular carcinoma. Oncol Rep 29: 946-950, 2013.

30. Kim K, Jutooru I, Chadalapaka G, Johnson G, Frank J, Burghardt R, Kim S and Safe S: HOTAIR is a negative prognostic factor and exhibits pro-oncogenic activity in pancreatic cancer. Oncogene 32: 1616-1625, 2013.

31. Xu ZY, Yu QM, Du YA, Yang LT, Dong RZ, Huang L, Yu PF and Cheng XD: Knockdown of long non-coding RNA HOTAIR suppresses tumor invasion and reverses epithelial-mesenchymal transition in gastric cancer. Int J Biol Sci 9: 587-597, 2013.

32. Kim HJ, Lee DW, Yim GW, Nam EJ, Kim S, Kim SW and Kim YT: Long non-coding RNA HOTAIR is associated with human cervical cancer progression. Int J Oncol 46: 521-530, 2015.

33. Wu Y, Zhang L, Zhang L, Wang Y, Li H, Ren X, Wei F, Yu W, Liu T, Wang X, et al: Long non-coding RNA HOTAIR promotes tumor cell invasion and metastasis by recruiting EZH2 and repressing E-cadherin in oral squamous cell carcinoma. Int J Oncol 46: 2586-2594, 2015.

34. Shinomiya N: New concepts in radiation-induced apoptosis: 'premitotic apoptosis' and 'postmitotic apoptosis'. J Cell Mol Med 5: 240-253, 2001.

35. Qiu JJ, Wang Y, Ding JX, Jin HY, Yang G and Hua KQ: The long non-coding RNA HOTAIR promotes the proliferation of serous ovarian cancer cells through the regulation of cell cycle arrest and apoptosis. Exp Cell Res 333: 238-248, 2015.

36. Chen J, Lin C, Yong W, Ye Y and Huang Z: Calycosin and genistein induce apoptosis by inactivation of HOTAIR/p-Akt signaling pathway in human breast cancer MCF-7 cells. Cell Physiol Biochem 35: 722-728, 2015.

37. Wang Q, Fan H, Liu Y, Yin Z, Cai H, Liu J, Wang Z, Shao M, Sun X, Diao J, et al: Curcumin enhances the radiosensitivity in nasopharyngeal carcinoma cells involving the reversal of differentially expressed long non-coding RNAs. Int J Oncol 44: $858-864,2014$ 